\title{
Play fighting versus serious fighting in golden hamsters (Mesocricetus auratus)
}

\author{
DAMIAN I. ONYEKWERE and J. MARTÍN RAMÍREZ \\ Universidad Complutense, Madrid, Spain
}

\begin{abstract}
The differences between play fighting and serious fighting in golden hamsters was investigated at different ages by using an isolated-rearing technique. The purpose of the experiment was to provide information on the effect of early isolation on both play fighting and serious aggression, and to demonstrate whether the identification criteria were different for both. The results supported the importance of early social experiences on both play fighting and serious aggression.
\end{abstract}

A behavior widespread among developing mammals, with an apparent similarity to the real aggression observed in adults, is play fighting. Although a vast number of possible explanations for play aggression have been suggested, there is little or no evidence to support its hypothetical functions (Smith \& Lewis, 1985). Given that the potential for engaging in particular behaviors evolves through natural selection, such a widespread behavior should contribute to individual survival and reproductive success, serving some important developmental function (cf. Boulton \& Smith, 1989).

Play aggression might serve the evolutionary function of enabling young individuals to practice, in a relatively safe, friendly, and enjoyable way, skills that will prove useful later in adult life. According to the "practice" hypothesis, it might be a kind of immature version of true aggressive behavior to prepare animals for adult fighting, providing an opportunity to rehearse attack and defense patterns in a nonserious context, that is, without threatening or intimidation of the opponent, which is the normal aim of serious aggression (Aldis, 1975; Fagen, 1981; Hole \& Einon, 1984; Meany, Steward, \& Beatty, 1985; Taylor, 1980). But it might also serve as a sort of training for future sexual behavior, as some common features would suggest. Classical reports on the deleterious influence of early social deprivation and its impairment of subsequent sexual behavior in many mammals (MacLusky \& Naftolin, 1981) seem to support this view. An alternative hypothesis holds that play fighting is rather a truly distinct and independently motivated form of behavior (Dieterlen, 1959; Goldman \& Swanson, 1975; Panksepp, Siviy, \& Normansell, 1984; Takahashi \& Lore, 1983).

An approach that has been used to investigate this argument is to raise animals in social isolation and com-

\footnotetext{
This research was supported by Grants 8255 from Junta de Andalucia and PM89-0175 from CICYT, as well as a grant from the Alexander von Humboldt Foundation to J.M.R. The helpful technical assistance of Khrist Sharp and Ana Maria Perrez Vilches is also acknowledged with gratitude. Address correspondence to J. Martín Ramírez, Calle Ramón Gómez de la Serna 87, 28035 Madrid, Spain.
}

pare their behavior during development and in adulthood with socially reared animals. Eight studies on the influence of isolation on intraspecific aggression in rats have been reported, using the resident-intruder paradigm. Five of the studies suggest that early social deprivation reduces aggression toward intruders (Allen \& Boyce, 1976; Blanchard \& Blanchard, 1980; Flannelly, Flannelly, \& Blanchard, 1984; Luciano \& Lore, 1975; Price, 1978), although the effect was significant in only two of them. In contrast, Wahlstrand, Knutson, and Viken (1983) found more fighting. And, finally, Takahashi (1986) and Potegal and Einon (1989) did not find any effect on later intraspecific aggression. It would be worthy, therefore, to replicate these inconsistent effects reported from using the rat-a species that has a rich social repertoire in adulthood-in a solitary rodent species such as the golden hamster (Mesocricetus auratus), and to compare them.

But, before evaluating why these animals fight playfully, therefore, we need a detailed description of their behavior. This behavioral description, which may vary from one species to another, would provide us with the main identification criteria needed for distinguishing between playful and serious fighting. For a spontaneous measure of play and serious fighting, the resident-intruder paradigm was investigated at different ages, using an isolated rearing technique.

Another purpose of this experiment was to provide information on the effect of early isolation on both play fighting and serious aggression, and to demonstrate whether the identification criteria were different for both.

\section{EXPERIMENT 1 \\ Isolation and Play Fighting During Development}

Method
Subjects. Thirty-two experimentally naive Syrian golden hamsters
of both sexes were used. All were born and reared in our own labora-
tory, and weaned at 21 days of age.
Materials. Hanging cages were of Maxiglas $(48 \times 27 \times 16 \mathrm{~cm})$ with
a $2-$ to $3-\mathrm{cm}$ layer of processed sawdust and wood shavings for bedding
material. The colony room was maintained under constant temperature,
at $21^{\circ}-23^{\circ} \mathrm{C}$, and under a $14: 10$-h light:dark cycle. All cages were
equipped with one external drinking bottle and a feeder. Water, food,
and nest materials were freely available, except during the testing periods.


Procedure. Two groups were formed. One group of two litters $(n=$ 16) was left under social rearing conditions ( 4 animals per cage) until the day of the test; in a second group of two litters $(n=8)$, the animals were separated at 46 days of age, and housed individually until the end of the experiment. The animals were tested under a resident-intruder paradigm in a glass cage $(60 \times 40 \times 35 \mathrm{~cm})$, with transparent walls, facilitating observation and videotape recording. The floor was covered with sawdust, which was renewed after each session. The subject used as a resident was introduced inside the experimental cage $30 \mathrm{~min}$ prior to the beginning of the observation session. This started with the introduction of the intruder, and lasted for $10 \mathrm{~min}$. At the conclusion of each observation period, each animal was returned to its respective home cage. Both resident and intruder were of the same age, sex, and rearing conditions, with corresponding weight matched in order to counterbalance the intruder's status and facilitate characterization. Animals of the same litter, however, were tested with unfamiliar animals and never with a littermate. Each resident was always tested with the same intruder throughout the experiment. Tests started for both groups at $\mathbf{4 8}$ days of age, that is, 2 days after the isolation of the second group. They were conducted on all subjects once every week thereafter until 78 days of age, when they were already sexually mature. Data were collected in the first $2 \mathrm{~h}$ of the dark cycle, under a dim, red incandescent light. The encounters were videotaped with a VHS Bosch video camera for subsequent detailed quantitative data analysis. The occurrence of fighting can vary as a function of time elapsed since the onset of an observation session (Wahlstrand et al., 1983), so treatment conditions were equated for the number of observations conducted within each of the successive 10-min experimental periods.

The measurement index was the frequency of pinning that occurred in each session, that is, how often 1 member of a pair stood over a partner held down on its back. Reversals of the relative position of both animals were counted as additional play fights. A bout was considered to have ended when the 2 animals ceased to maintain ventral-ventral contact for more than $3 \mathrm{sec}$. This index was selected for the sake of simplicity and objectivity, and because it affords some advantages during quantification.

\section{Results}

During the early days of their life (8-18 postnatal days), even before opening their eyes, the hamsters exhibited behavioral patterns that were later transformed into ones that were clearly characterized as play fighting. The behavioral patterns typical of play fighting were pinning and supine position, followed by tumble and rolling, with a constant role reversal. Pinning was initiated by pushing the snout through the abdomen of the opponent or by contacts around the nape. A juvenile pinned and attacked the other's cheek; the recipient reciprocated by rotating around its longitudinal axis, shifting the cheek away from the attacker, and launching counterattacks, reversing the roles. The roles were not well established; it was difficult to determine which subject had the initiative and which was acting as defender. Sometimes one of the opponents adopted a supine posture even before any physical contact was produced, and apparently with no confrontational motives for starting a fight. Another phenomenon was the relaxed mood that was displayed during play fighting. Most of the time, during supine/pinning interaction, the pinning animal directed its attention elsewhere, while still holding the supine subject. The hamsters' main target was the side of the face and the cheek pouches, which were gently bitten and nibbled. The bites were gentler than in serious fighting, showing no wounds, sharp squeals, or fleeing from the defender. Gentle biting and soft pulling are very similar to what male hamsters do in sexual encounters. There were occurrences of snout jerking that were not fixed to any specific area of the body, but were always rotated and accompanied with "beats," mostly to the upper ventral sites of the opponent.

With increasing age, there was remarkably little change in the targets and tactics used for play fighting. No new behavioral patterns were introduced into the hamsters' play fighting, although, from the onset of sexual maturity, these counterattacks decreased in proportion to the decrease in play fights. This decline in the frequency of play fighting, with fewer role reversals, was concomitant with an increasing appearance of some aggressive behavioral patterns, which would become quite predominant during adulthood. But there was never a total replacement; play fighting's components remained in a lesser form in the animals' repertoire for a long time, as they were observed at times between mothers and pups and even between adults.

In the resident-intruder paradigm, the animals isolated for only $48 \mathrm{~h}$ after being group-housed for 46 days, fought more than the uninterrupted socially reared ones from the time of the first session on. This trend was maintained throughout the entire study. With the onset of sexual maturity, the isolated animals were also the ones that engaged more in agonistic encounters. The same animals were capable of switching from this conflict situation to a more playful mood. The on top/on bottom position, typical of play fighting, could also be performed during the occasional serious fighting occurring at this age. When this happened, it ended up forming a clinch that was consequently followed by kicking and pushing by the defending animal (on the bottom). On the contrary, during play fighting, there was no such reaction.

\section{EXPERIMENT 2 Isolation and Serious Fighting in Adult Hamsters}

\section{Method}

Nineteen experimentally naive male Syrian golden hamsters were used. Eight were left under social rearing conditions ( 2 animals per cage) until the day of the test, and 11 were separated at weaning ( 21 days of age) and housed individually until the end of the experiment. The breeding and housing conditions and procedure were the same as described for Experiment 1. Tests started at $\mathbf{8 5}$ days of age. The total number of attacks (chasing, clinch, bites) launched by the resident toward the in truder during the session was used as a measurement index.

\section{Results}

At 85 days of age, a fighting pattern very close to that described as serious aggression, with an obviously clearcut aggressive-defensive role division, was observed. Dominance, offensive initiatives, and attack patterns (e.g., chasing, biting, lateral threat, climbing on top, and clinch) prevailed in the resident, whereas reactive and defensive patterns (escape, moving away, upright boxing posture, immobility, screeching, and defecation) were displayed by the intruder. The partner standing over the supine animal would be more likely to bite aggressively if its partner tried to counterattack, in contrast to play fighting, which allowed counterattack without biting. Usually, in this seri- 
ous fighting context, the attacker's clinch was immediately followed by kicking by the defender. Threats and hard bites by the attacker and fleeing from the pursuerthe typical adult evading tactics-by the defender, were also observed in this agonistic behavior. In the extreme case of total defeat, a cataleptic immobile posture was adopted. The target that was attacked during serious fighting was the rump or flank of the opponent. The resident directed hard bites to the lateral areas of the intruder, which responded with vocalizations and defense movements. Sometimes the latter showed a sort of "walking on tiptoes" behavior; the animal walked very slowly with one of its rear legs lifted. This behavior, typical of the defeated animal, reduced the attack behavior. Instead of chasing and biting, the resident shifted into more sniffing and other inspection patterns.

Using the same resident-intruder paradigm as in Experiment 1 , the adult hamsters showed a trend very similar to the one observed in the younger animals: the isolated animals displayed a higher frequency of serious aggression than those that were socially reared. Although the latter group emitted practically no agonistic behavior during the testing periods, they did have occasionally intense periods of serious fighting in their home cages.

\section{GENERAL DISCUSSION}

The present results tend to support the importance of early social experiences on both play fighting and serious aggression, as well as a positive correlation between play fighting and serious aggression. The earlyisolated hamsters tended to have shortened attack latencies and to increase the frequency and duration of both behaviors. In developing hamsters, it has been observed that the earliest isolated animals were the ones with more play fighting (Onyekwere \& Ramirez, unpublished raw data). In rats, it has also been observed that even a short period of isolation increases the frequency of play fighting (Panksepp, 1981; Thor \& Holloway, 1984). The locomotor hyperactivity, previously demonstrated in isolated rats (Einon, Morgan, \& Kibbler, 1978), could also account for these results-greater locomotion would bring these animals into contact more frequently, resulting in a higher rate of play fighting. In accordance with Scott's (1966) and Einon \& Morgan's (1977) suggestions, isolation during critical periods of socialization seems to have significant and lasting effects on aggression.

Their nearly identical motor patterns could result in very misleading interpretations, except when an adequate comparison of the differences of both play fighting and serious fighting in golden hamsters is made. Although both behaviors appear to share similar patterns, their differences must not be ignored. According to Miller (1973), it is not any individual criterion that distinguishes play fighting from serious aggression, but it is rather the combined subjective impression produced by all the characteristics that provides this distinction. Hamsters show different targets and tactics for play fighting and for serious aggression. In rats, however, a gradual transition of behavioral patterns occurs throughout the developmental period-as the animals approach sexual maturity, they increasingly begin to use more adult-like patterns in their play fighting (Hole \& Einon, 1984; Meaney \& Steward, 1981). In hamsters, both play fighting and serious aggression remain distinct at all ages, with no gradual transition from one to the other. At the onset of sexual maturity, play fighting shows little change in its form, but what is observed is a clear decline of its frequency and duration. Play fighting, very long-lasting between weaning and the onset of sexual maturity (about $1 \mathrm{~min})$, then declines (60-70 days) to only about $3 \mathrm{sec}$ (Pellis \& Pellis, 1988). Interestingly, in rats, an absence of age-related changes in bout duration as well as in the number of role reversals have been reported (Hole, 1988). In contrast to Goldman and Swanson's (1975) assertion that the golden hamster ceases to play altogether in early adult- hood, we have also observed play fighting between mothers and pups, and even between male adults. This behavior has also been clearly reported in studies with rats: all the female and heterosexual pairs and half of the male pairs tested between 60 and 90 days of age (after the onset of sexual maturity) continued to engage in play fighting (Takahashi \& Lore, 1983). Play fighting, therefore, is not confined strictly to immature animals, as suggested by some researchers (e.g., Baeninger, 1967), although it declines abruptly to a low level in males, which, incidentally, were involved in significantly more and longer play fighting than females at earlier ages (Hole, 1988).

Most muroid rodent species provide an unambiguous difference between targets of both behaviors. During serious adult fighting, golden hamsters attack the rump and lower flanks, and during play fighting, animals of both sexes gently bite mainly the side of the face and the cheek pouches, as we have previously mentioned (Pellis \& Pellis, 1987, 1988). There are exceptions, however. Other species, such as the Columbian ground squirrel (Spermophilus columbianus; Steiner, 1971), the Oriental small-clawed other (Amblonix cinerea; Pellis, 1984), and the European polecat (Mustela putorius; Poole, 1966), appear to have the same targets in both behaviors. Tactics are also different in hamsters. The lateral display frequently used during serious aggression (Grant \& Mackintosh, 1963), as well as threats, loud squeals, and serious injuries when bitten, are absent during play fighting. Play fighting is characterized by the presence of play signals such as the playface and pinning, by the role reversal between partners that may even be a different size, and by a relaxed muscle tone that is not common during serious aggressive encounters. The sequence of these behaviors varies and repeats.

These cross-species differences in play fighting have been largely attributed to species-specific differences in targets, tactics, body shape, and so on, until Aldis (1975). Some of this diversity, however, is of a more fundamental kind; it represents different themes or types of targets, besides the agonistic one, such as sexual encounters, social investigation, and allogrooming, labeled as amicable targets by Pellis (1988). These nonagonistic targets appear to be borrowed from other behavioral contexts in which contact is promoted. According to Pellis, the predominant target seen in play fighting in golden hamsters-the cheek pouches, which are gently attacked-is not of agonistic character, but appears to be a sociosexual target. In fact, the cheek is not attacked during serious aggression, even when the intruder is anesthetized, but it is contacted during social investigatory contacts. With the onset of sexual maturity, male contacts to the posterior cheek area of the female, such as gentle bites or ear grooming, were significantly more frequent during sexual encounters (see Siegel, 1985, for general information on this species and others) than during contact between same-sex strangers. In other muroid rodents, such as rats, deer mice, and montane voles, the same targets contacted during play fighting and sociosexual behavior are also reported (Pellis \& Pellis, 1989). In rats, the ones that performed more play fighting were also the ones performing more precocial sexual behavior, which was reflected in mounting (Hole \& Einen, 1984); and in both of them, the piloerection response, a typical component of agonistic interactions that is used as a good index for identification (Takahashi \& Lore, 1983), is absent. Whereas the golden hamsters used amicable targets, such as the sociosexual one described above, other species may differ in the kinds of targets observed during play fighting. For example, Djungarian hamsters (Phodopus campbelli) involve both sexual (mouth) and agonistic (rump and dorsum of head) targets; others may employ agonistic ones.

In conclusion, if play aggression were in accordance with the "practice"' hypothesis, then one might expect its targets and tactic patterns to be similar to the adult patterns of serious aggression, and with the onset of sexual maturity, both to become indistinct, merging one into the other. This is clearly not the case. Our data on golden hamsters confirm previous reports that did not support this hypothesis (Pellis \& Pellis, 1987): (1) their targets were different; (2) the consequences appeared to differ considerably-during play fighting they competed for amicable targets, but not for agonistic ones; ( 3 ) behavior patterns needed during serious aggression were not those released during play fighting; and (4) there was not a gradual transition from play fighting to serious aggression, but rather, whenever it occurred, it involved an abrupt change. In rats, further differences with respect to eliciting factors have been reported (Thor \& Holloway, 1984); play fighting is independent of olfactory influence, which is unlike that of adult fighting (Alberts \& Galef, 1973). 
If any relationship with the practice of play fighting should be found, it would be with sexual behavior; many behavioral patterns seen during play fighting are also performed during sexual encounters. Would these pronounced similarities allow us to wonder whether play fighting could be, at least partially, an immediate precursor of sexual instead of aggressive behavior?

Play fighting remains a distinct form of behavior, not only throughout ontogeny, but at all ages. In adulthood, it is not totally eliminated. Its decline, therefore, does not seem to be due to an escalation of serious adult aggression; the animals displaying the more playful attacks were the ones most likely to bite later in life. It may be better explained by a decrease in motivation to attack playfully, and attenuated by the inhibitory effect of retaliatory bites. What decreases is the ability to maintain a stable playful mood-older animals show a marked reduction in the duration of play fighting and can slip into more serious aggression because their playful mood becomes increasingly difficult to maintain (Pellis \& Pellis, 1988, 1990). Further research is needed to determine the extent to which play fighting, which changes quantitatively rather than qualitatively, in hamsters' ontogeny, can be related to adult behavior.

\section{REFERENCES}

AlberTs, J. R., \& GALEF, B. G. (1973). Olfactory cues and movement: Stimuli mediating intraspecific aggression in the wild Norway rat. Journal of Comparative \& Physiological Psychology, 85, 233-242. Aldis, O. (1975). Play fighting. New York: Academic Press.

Allen, J. A., \& Boyce, R. (1976). Effects of rearing on homosexual behavior in the male laboratory rat. Bulletin of the Psychonomic Society, 23, 321-322.

BAENinger, L. P. (1967). Comparison on behavioural development in socially isolated and grouped rats. Animal Behaviour, 15, 367-371.

BlanchaRd, R. J., \& BlanchaRD, D. C. (1980). The colony model: Experience counts. Behavioral Neural Biology, 30, 109.

Boulton, M., \& SMith, P. K. (1989, July). Play fighting and serious fighting in children: Perception and action. Paper presented at the meeting of the International Society for the Study of Behavioural Development, Jyvaskyla, Finland.

Dieterlen, F. (1959). Des Verhalten des syrischen Gold hamsters. Zeitung für Tierpsychologie, 16, 47-103.

EINON, D. F., \& MoRgan, M. J. (1977). A critical period for social isolation in the rat. Developmental Psychobiology, 10, 123-132.

Einon, D. F., Morgan, M. J., \& KibBler, C. C. (1978). Brief periods of socialization and later behavior in the rat. Developmental Psychobiology, 10, 123-132.

FAGEN, R. M. (1981). Animal play behavior. New York: Oxford University Press.

Flannelly, K. J., Flannelly, L., \& Blanchard, R. J. (1984). Adult experience and the expression of aggression: A comparative analysis. In K. J. Flannelly, R. J. Blanchard, \& D. C. Blanchard (Eds.), Biological perspectives on aggression. New York: Raven Press.

Goldman, L., \& Swanson, H. H. (1975). Developmental changes in pre-adult behavior in confined colonies of golden hamster. Developmental Psychobiology, 8, 137-150.

Grant, E. C., \& MaCKINTOSH, J. H. (1963). A comparison of the social postures of some common laboratory animals. Behaviour, 34, 256-259.

HoLE, G. J. (1988). Temporal features of social play in the laboratory rat. Ethology, 78, 1-20.

Hole, G. J., \& EINON, D. (1984). Play in rodents. In P. K. Smith (Ed.), Play in animals and man (pp. 95-117). Oxford: Basil Blackwell.

LuCIANO, D., \& LORE, R. (1975). Aggression and social experience in domesticated rats. Journal of Comparative \& Physiological Psychology, 88, 917-923.

MacLusky, N. J., \& Naftolin, F. (1981). Sexual differentiation of the central nervous system. Science, 211, 1294-1302.

Meany, M. J., \& STEWARD, J. (1981). A descriptive study of social development in the rat, Rattus norvegicus. Animal Behaviour, 29, 34-45.

Meany, M. J., Steward, J., \& Beatty, W. W. (1985). Sex differ- ences in social play: The socialization of sex roles. Advanced Study Behavior, 15, 1-58.

Mendoza, D. L., \& Ramirez, J. M. (1987). Play in kittens and its association with cohesion and aggression. Bulletin of the Psychonomic Society, 25, 27-30.

Miller, S. (1973). Ends, means, and galumphing: Some leitmotifs of play. American Anthropologist, 75, 87-98.

PANKSEPP, J. (1981). The ontogeny of play in rats. Developmental Psychobiology, 14, 327-332.

PanksePP, J., SiviY, S., \& Normansell, L. (1984). The psychobiology of play: Theoretical and methodological perspectives. Neuroscience Biobehavioral Biology, 30, 197-206.

Pellis, S. M. (1984). Two aspects of play fighting in a captive group of Oriental small-clawed otters, Amblonyx cinerea. Zeitschrift für Tierpsychologie, 65, 77-83.

Pellis, S. M. (1988). Agonistic versus amicable targets of attack and defense: Consequences for the origin, function, and descriptive classification of play fighting. Aggressive Behavior, 14, 85-104.

Pellis, S. M., \& Peluis, V. V. (1987). Play fighting differs from serious fighting in both target of attack and tactics of fighting in the laboratory rat, Rattus norvegicus. Aggressive Behavior, 13, 227-242.

Pellis, S. M., \& Pellis, V. V. (1988). Identification of the possible origin of the body target that differentiates play fighting from serious fighting in Syrian golden hamsters, Mesocricetus auratus. Aggressive Behavior, 14, 437-449.

Pellis, S. M., \& Pellis, V. V. (1989). Targets of attack and defense in play fighting of the Djungarian hamster, Phodopus campbelli. Aggressive Behavior, 15, 217-234.

Pellis, S. M., \& Pellis, V. V. (1990). Differential rates of attack, defense, and counterattack during the developmental decrease in play fighting by male and female rats. Developmental Psychobiology, 23, 215-231.

Poole, T. B. (1966). Aggressive play in polecats. Symposium of the Zoological Society of London, 18, 81-94.

Poole, T. B., \& Fish, J. (1976). An investigation of individual, age and sex differences in the play of Rattus norvegicus. Journal of Zoology, London, 179, 249-260.

Potegal, M., \& EINON, D. (1989). Aggressive behaviors in adult rats deprived of playfighting experience as juveniles. Developmental Psychobiology, 22, 159-172.

Price, E. O. (1978). Genotype versus experience effects on aggression in wild and domestic Norway rats. Behaviour, 64, 340-353.

ScotT, J. P. (1966). Agonistic behavior of mice and rats: A review. American Zoologist, 6, 683-701.

Siegel, H. J. (1985). Aggressive behavior. In H. I. Siegel (Ed.), The hamster (pp. 261-286). New York: Plenum.

SMITH, P. K., \& LEWIS, K. (1985). Rough-and-tumble play, fighting, and chasing in nursery school children. Ethology \& Sociobiology, 6 , 175-181.

STEINER, A. L. (1971). Play activity of Columbian ground squirrels. Zeitung für Tierpsychologie, 28, 247-261.

Takahashi, L. K. (1986). Post weaning environment and social factors influencing the onset and expression of agonistic behavior in Norway rats. Behavioral Processes, 12, 237-260.

TAKahashi, L. K., \& LoRE, R. K. (1983). Play fighting and the development of agonistic behavior in male and female rats. Aggressive Behavior, 9, 217-227.

TAYLOR, G. T. (1980). Fighting in juvenile rats and the ontogeny of agonistic behavior. Journal of Comparative \& Physiological Psychology, 94, 953-961.

ThOR, D. H., \& Holloway, W. R. (1984). Sex and social play in juvenile rats, Rattus norvegicus. Journal of Comparative Psychology, 98, 276-284.

Wahlstrand, K., KnUtson, J. F., \& Viken, R. J. (1983). Effects of isolation during development on reactivity and home-cage agonistic behavior in rats. Aggressive Behavior, 9, 29-40.

(Manuscript received May 6, 1993.) 